\title{
Land Cover, Extent, and Properties of Arenosols in Southern Africa
}

\author{
Alfred E. Hartemink and Jan Huting \\ ISRIC - World Soil Information, Wageningen, The Netherlands
}

\begin{abstract}
Arenosols cover about 13\% in Sub-Saharan Africa and are widely spread in the southern part of the continent. Knowledge about the spatial distribution, properties, and land cover of Arenosols can be used to design programs to alleviate the major constraints for agricultural production. This article reviews the importance of Arenosols in eight countries of Southern Africa (Angola, Botswana, Lesotho, Mozambique, Namibia, South Africa, Swaziland, and Zimbabwe). Estimates of their extent are based on SOTER databases. The total extent of Arenosols in the eight countries is 169 million ha: extensively in Angola and Botswana (>50\% of total land area) but also in Zimbabwe, South Africa, and Mozambique (>15\% of total land area). About 26.3 million ha of Arenosols are under forest; 104.7 million ha under savannah and 3.5 million ha is desert and dunes. In total, 6.5 million ha of Arenosols are under agriculture cropland, most of which is located in Angola, Botswana, and South Africa. Arenosol topsoils in Namibia and South Africa are mostly alkaline but in Angola and Zimbabwe, the average topsoil pH of Arenosols is below 6. Organic carbon is uniformly low in Arenosols of Southern Africa and rarely exceeds $10 \mathrm{~g} \mathrm{~kg}^{-1}$. Higher C contents are found in soils with slightly higher clay content, whereas higher $C$ levels are also associated with higher cation exchange capacities (CECS). The low CEC and low water-holding capacity necessitates the addition of organic manures to increase agricultural production on Arenosols in Southern Africa.
\end{abstract}

Keywords agricultural land use, Global Soils and Terrain Digital Database (SOTER), sandy soils

Environmental factors, including poor soil conditions, are important drivers for food insecurity in Southern Africa. Spatial analysis of environmental conditions in relation to poverty and hunger is yet to be made and such analysis should indicate where the problem soils occur in association with agricultural land uses.

Sandy soils occur in all parts of the world. Soils that have more than $70 \%$ sand $(0.05-2.0 \mathrm{~mm})$ and less than $15 \%$ clay $(<0.002 \mathrm{~mm})$, are classified as Arenosols in the World Reference Base (FAO, 2001) and in taxonomy as sandy Entisols: Psamments when well-drained, or as Psammaquents when in tidal marshes, deltas, and wet (Soil Survey Staff, 1999). About 21\% of the Arenosols occur in Australasia, and $10 \%$ in South and Southeast Asia. About $51 \%$ of the Arenosols of the world are found in Africa. Less than 14\% of the global extent of Arenosols is

Received 27 February 2007; accepted 30 October 2007.

We are grateful to ir Koos Dijskhoorn of ISRIC - World Soil Information who compiled the SOTER database for Southern Africa and to Dr. David Dent for useful comments on the draft of this article. We thank the comments and suggestions by two anonymous reviewers.

Address correspondence to Dr A. E. Hartemink, ISRIC - World Soil Information, P.O. BOX 353, 6700 AJ Wageningen, The Netherlands. E-mail: Alfred.Hartemink@wur.nl 
found in South and Central America and only small patches are found in North America and Europe. Worldwide, Arenosols cover approximately 900 million ha compared to about 300 million ha of Vertisols and 700 million ha of Ferralsols. Yet, they have not received much research attention - possibly not many of the Arenosols are used for agriculture or only in a very limited way (i.e., for grazing or fuel wood collection).

For Southern Africa, the first regional estimate of Arenosol extent was made for the 1:5 million scale Soil Map of the World (FAO-Unesco, 1977). The map was largely based on soil surveys at the reconnaissance level (1:100 000 and smaller) conducted in the 1950s and 1960s. For Namibia, for example, only general information with local soil observations was available. The total extent of Arenosols in Angola, Botswana, Mozambique, Namibia, South Africa, and Zimbabwe was estimated to be 194 million ha (FAO-Unesco, 1977). In 1997, Eswaran et al. estimated that Arenosols in Africa cover about 273 million ha or almost $13 \%$ of the total land mass (Eswaran, Almaraz, Vandenberg, and Reich, 1997). They occur widely in the western part of the continent.

Most Arenosols are located in arid or semi-arid regions (van Wambeke, 1992). Arenosols are generally weakly developed with often less distinct soil horizonation. They may have developed in residual sands, in the weathering products of quartzrich rock, or in recently deposited sands of deserts and beaches (FAO, 2001). Chemical weathering is generally slow because of the prevalent hot and dry conditions. Physical weathering is dominant because of extreme changes in temperatures between day and night and between seasons. Erosion by wind is a problem in many areas due to the lack of soil cover and weak soil structure (FAO, 2001). Characteristic properties of Arenosols are high water permeability, low water-holding capacity, low specific heat, and often minimal nutrient contents. In summary, Arenosols have many attributes unfavorable for sustainable agriculture (van Wambeke, 1992), but in many parts of Southern Africa, Arenosols are increasingly used for arable farming because of the high population growth (Abalu and Hassan, 1998).

Strategies are needed to alleviate soil constraints for increased agricultural production. Such strategies should be based on a thorough understanding of the natural resources on which agricultural production depends, which include knowing where the problem soils are and what properties they have and how these soils are being used. We extracted these data from the SOTER databases for Southern Africa (FAO-ISRIC, 2003). The extent was matched with the recent land cover map of Africa (Mayaux et al., 2003).

The objectives of this study was to (i) estimate the extent of Arenosols in southern Africa, (ii) match the SOTER database with the land cover map to calculate the extent of different land cover classes under Arenosols, and (iii) to summarize the main soil chemical and physical properties of Arenosols in southern Africa.

\section{Databases and Methods}

\section{SOTER Databases}

Since the mid 1980s, a global soil and terrain database has been developed at a scale of 1:1 million, named Global Soils and Terrain Digital Database (SOTER). Each SOTER database is comprised of two main elements, a geographical 
component and an attribute data component. The geographical database holds information on the location, extent, and topology of each SOTER unit. The nonspatial attribute database of SOTER holds information of a maximum of 118 soil and terrain attributes for each map polygon (Oldeman and van Engelen, 1993). SOTER is to replace the 1:5 million FAO-Unesco soil map of the world (van Engelen and Hartemink, 2000). Continental scale SOTER databases are available for Latin America and the Caribbean, Central and Eastern Europe, Southern Africa, and Central Africa. The SOTER methodology has been applied at scales ranging from 1:250,000 to 1:5 million (Batjes, 2004) and a range of single value maps or data and interpretative products can be extracted. SOTER has been used in studies on vulnerability assessment to pollution mapping in Central and Eastern Europe, the impact of erosion on crop productivity in various tropical countries, global environmental change studies and agro-ecological zoning (Batjes, 2002, 2004). SOTER databases can also be combined with remote sensing imagery to investigate links between soils and land use.

SOTER consists of units (map polygons) that contain a distinctive, often repetitive, pattern of landform, lithology, surface form, slope, parent material, and soil. SOTER puts emphasis on the relationships between landform, parent material, and soils, integrating these into one unit: the SOTER unit. Each SOTER unit represents a unique combination of terrain and soil characteristics and as SOTER units consist of a combination of a terrain and soil component, they may contain several soil components. For example, a SOTER unit may consist of one or more terrain components and each terrain component may consist of one or more soil components. Thus, a SOTER unit can consist of $60 \%$ Ferralsols (Soil Taxonomy: Oxisols), $20 \%$ Vertisols, and 20\% Acrisols (Ultisols in Soil Taxonomy), or a unit may have 80\% Vertisols and 20\% Fluvisols (Soil Taxonomy: Fluvents).

\section{Southern Africa}

In early 2000, FAO and ISRIC - World Soil Information started to compile a SOTER database for Southern Africa. It included the compilation and harmonization of a soil and terrain digital database for eight countries in Southern Africa (FAO-ISRIC, 2003) using available soil maps and soil and terrain data including digital elevation models. The database has a generalized scale of 1:2 million, but the detail and quality or information varies widely between and within countries (Dijkshoorn, 2003). For example, in South Africa SOTER units are based on a scale of 1:250,000, whereas in several other countries SOTER units are based on a scale 1:1 million or smaller. SOTER units in Southern Africa are composed of up to seven soil components, with an average of two. Each soil component within a SOTER unit is described by one soil profile, identified by national soil experts as being representative. In total, there are 1092 soil profiles in the SOTER database of Southern Africa; of these 150 are Arenosols (Table 1). From the database, SOTER units were selected where Arenosols occurred. The extent of all polygons containing Arenosols was calculated using the X-tools extension in ArcView 3.3 (ESRI - Environmental Systems Research Institute, Redlands, California); the projection was set to Lambert Equal-Area Azimuthal (central meridian $25^{\circ} \mathrm{E}$, reference latitude $20^{\circ} \mathrm{S}$ ). Successively, soil profile and soil component data were linked in MS Access and these were imported in ArcView to produce the distribution of Arenosols in the eight countries. 
Table 1. Number of SOTER units and soil profiles for the eight countries in Southern Africa

\begin{tabular}{lrcrrr}
\hline Country & $\begin{array}{c}\text { SOTER units } \\
\text { (polygons) }\end{array}$ & $\begin{array}{c}\text { Terrain } \\
\text { components }\end{array}$ & $\begin{array}{c}\text { Soil } \\
\text { components }\end{array}$ & $\begin{array}{c}\text { Number of } \\
\text { soil profiles }\end{array}$ & $\begin{array}{c}\text { Number of } \\
\text { Arenosol } \\
\text { profiles }\end{array}$ \\
\hline Angola & 236 & 324 & 889 & 231 & 60 \\
Botswana & 95 & 145 & 404 & 63 & 6 \\
Lesotho & 25 & 40 & 96 & 39 & 0 \\
Mozambique & 226 & 325 & 641 & 164 & 30 \\
Namibia & 93 & 118 & 269 & 56 & 3 \\
South Africa & 3,041 & 7,010 & 11,828 & 335 & 39 \\
Swaziland & 18 & 34 & 72 & 31 & 0 \\
Zimbabwe & 146 & 201 & 297 & 173 & 12 \\
Total & 3,880 & 8,197 & 14,496 & 1,092 & 150 \\
\hline
\end{tabular}

The total extent of Arenosols was summed up for each country. The map shows the polygons in which the extent of Arenosols exceeds $75 \%$.

\section{Land Cover Map}

The land cover map of Africa has been used to identify land cover classes in Southern Africa (Mayaux et al., 2003). The grid map of 1-km spatial resolution shows the major vegetation formation of the continent with an improved thematic content over previous land cover maps. The data were acquired in 2000 by SPOT-4 VGT (CNES Centre National d'Etudes Spatiales, France). The land cover raster was vectorized in ArcView. The map identifies 24 land cover classes but we reduced the number to 18 classes with five broad land cover classes (forest, savanna, cropland, deserts, and other land cover classes including waterbodies, cities, and urban areas). From this land cover map, the total area was calculated for each land cover class. The SOTER Arenosol map was intersected with the land cover map using ArcView 3.3. For each of the polygons with more than $75 \%$ Arenosols, the extent of the 18 land cover classes was calculated; these were summed up per country.

\section{Soil Analytical Methods}

The soil chemical and physical properties of the 150 Arenosol profiles were taken from the SOTER database. The analytical methods were as follows:

Preparation: Sample is air-dried, cleaned, crushed (not ground), passed through 2-mm sieve, homogenized. Moisture content is determined at $105^{\circ} \mathrm{C}$. The $\mathrm{pH}-\mathrm{H}_{2} \mathrm{O}: 20 \mathrm{~g}$ of soil is shaken with $50 \mathrm{ml}$ of water for $2 \mathrm{~h}$, electrode in upper part of suspension; $\mathrm{pH}-\mathrm{KCl}$ : likewise but shaken with $1 \mathrm{M} \mathrm{KCl}$.

Particle-size distribution: $20 \mathrm{~g}$ soil is treated with hydrogen peroxide $15 \%$ overnight in the cold, then in waterbath at ca. $80^{\circ} \mathrm{C}$. Then boiled on hot plate for $1 \mathrm{~h}$. Washings until dispersion. Dispersing agent is added (20-ml solution of $4 \%$ Na-hexameta-phosphate and $1 \%$ soda) and suspension shaken overnight. 
Suspension sieved through $50-\mu \mathrm{m}$ sieve. Sand fraction remaining on sieve dried and weighed. Clay and silt determined by pipetting from sedimentation cylinder.

Exchangeable bases and CEC: Percolation with $1 \mathrm{M} \mathrm{NH}_{4} \mathrm{OAc} \mathrm{pH} 7$ using automatic extractor. Cations are determined in the leachate by atomic absorption spectrometer (AAS).

CEC: saturation with sodium acetate $1 \mathrm{M}$ pH7; washed with ethanol $80 \%$ and then leached with NH4OAc $1 \mathrm{M}$ pH7. In South Africa, CEC was determined by the Peech method at $\mathrm{pH} 8$ (Peech, 1965). Na determined by flame emission spectrometer (FES).

Exchangeable acidity and aluminium: The sample is extracted with $1 \mathrm{M} \mathrm{KCl}$ solution and the exchanged acidity $(\mathrm{H}+\mathrm{Al})$ titrated with $\mathrm{NaOH}$. $\mathrm{Al}$ is measured by AAS. Organic carbon by the Walkley-Black procedure.

Total nitrogen: Micro-Kjeldahl. Moisture determinations on undisturbed core samples in silt box (pF1.0; 1.5; 2.0) and kaolinite box (pF2.3; 2.7), respectively, and on disturbed samples in high pressure pan ( $\mathrm{pF} 3.4 ; 4.2)$. Bulk density obtained from dry weight of core sample.

\section{Results}

\section{Extent and Land Cover}

Arenosols occupy large areas from Angola and Namibia to Zimbabwe and Botswana (Figure 1). The Arenosols in large areas of Botswana and in surrounding

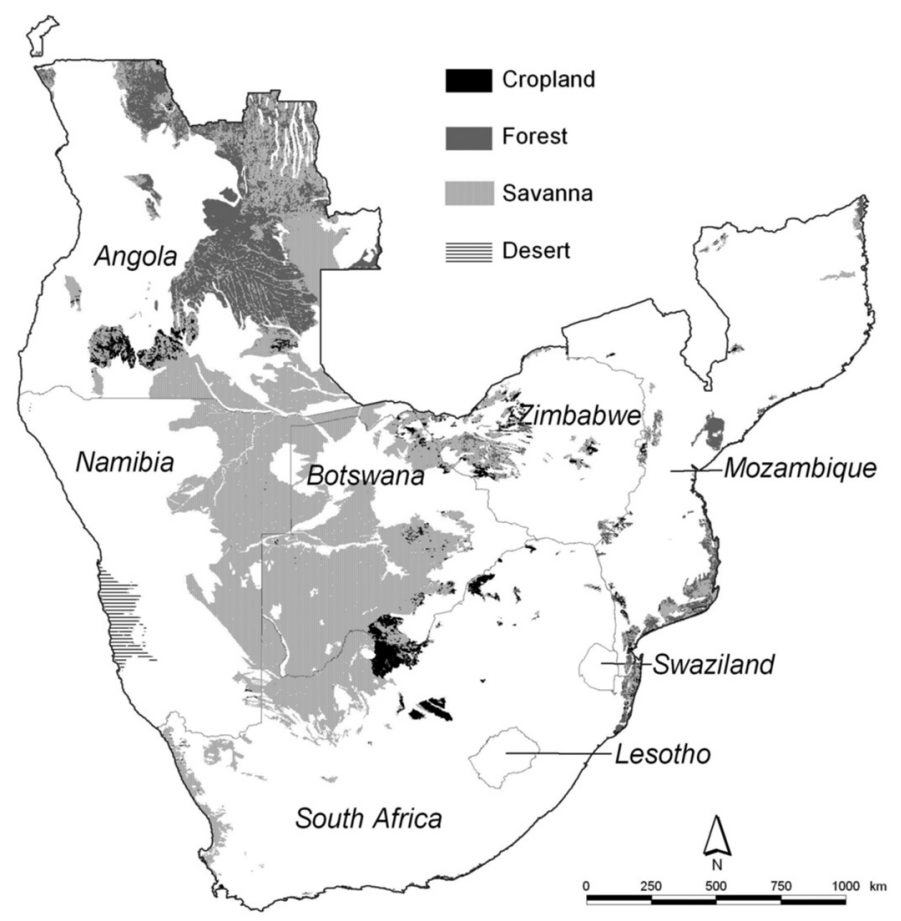

Figure 1. Simplified land-cover map of Arenosols in Southern Africa, based on SOTER and land cover map of Mayaux et al. (2003). 
Table 2. Extent of Arenosols, total area under cropland, and total area of Arenosols under cropland in Southern Africa

\begin{tabular}{|c|c|c|c|c|c|c|}
\hline \multirow[b]{2}{*}{ Country } & \multirow[b]{2}{*}{$\begin{array}{l}\text { Land area } \\
\text { million ha }\end{array}$} & \multicolumn{2}{|c|}{ Arenosols } & \multicolumn{3}{|c|}{$\begin{array}{c}\text { Total area of Arenosols under } \\
\text { cropland }\end{array}$} \\
\hline & & $\begin{array}{l}\text { Million } \\
\text { ha }\end{array}$ & $\%$ & $\begin{array}{l}\text { Million } \\
\text { ha }\end{array}$ & $\begin{array}{l}\% \text { of total } \\
\text { extent } \\
\text { Arenosols }\end{array}$ & $\begin{array}{l}\% \text { of total } \\
\text { area under } \\
\text { cropland }\end{array}$ \\
\hline Angola & 125.2 & 63.4 & 50.6 & 1.9 & 3.0 & 38.2 \\
\hline Botswana & 57.9 & 38.2 & 66.0 & 1.1 & 2.9 & 23.1 \\
\hline Lesotho & 3 & 0 & 0.0 & 0 & 0.0 & 0.0 \\
\hline Mozambique & 79 & 16.8 & 21.3 & 0 & 0.0 & 0.0 \\
\hline Namibia & 82.7 & 25.7 & 31.1 & $<0.1$ & $<0.1$ & 0.0 \\
\hline South Africa & 125.2 & 18.1 & 14.5 & 2.6 & 14.4 & 10.2 \\
\hline Swaziland & 1.7 & 0 & 0.0 & 0 & 0.0 & 0.0 \\
\hline Zimbabwe & 39.3 & 6.4 & 16.3 & 0.9 & 14.1 & 7.8 \\
\hline Total & 514.0 & 168.6 & & 6.5 & & \\
\hline
\end{tabular}

countries are derived from the Kalahari Sands. In Zimbabwe, the Arenosols have been derived mostly from weathering of the underlying granitic rocks that contain large amounts of quartz (Burt et al., 2001).

The total area of Arenosols in the eight countries is estimated to be 168.6 million ha. The largest extent is found in Angola (63.4 million ha) where Arenosols cover about $51 \%$ of the total land area. In Botswana, Arenosols occupy 38.2 million ha or two-thirds of the whole country (Table 2). Arenosols are also widespread in Namibia where they cover 25.7 million ha or $31 \%$ of the total land mass. Arenosols also occupy large areas in Mozambique, South Africa, and Zimbabwe.

From the land cover map, it was calculated that most of the Arenosols in Southern Africa are under savannah vegetation with or without shrubs (105 million ha) (Table 3). Arenosols with deciduous woodland and open grasslands with shrubs cover tens of millions of ha throughout Southern Africa. About 26 million ha is under forest, mostly in Angola. Of the 169 million ha of Arenosols in Southern Africa, about 6.5 million ha are under agricultural crops. The largest extent is found in South Africa (2.6 million ha) but also in the south central part of Angola where there are 1.9 million ha of Arenosols cultivated. Considerable areas of Arenosols in Zimbabwe and South Africa are also under cropland (Figure 1).

There is a difference in the extent of Arenosols in Tables 2 and 3. The extent in Table 2 is based solely on the SOTER polygons that have $75 \%$ or more Arenosols. In Table 3, these polygons are combined with the land cover raster. The land cover classes occur within polygons but as the polygons are not $100 \%$ pure Arenosols there is a deviation between the sum of the land cover classes under Arenosols and the total extent of Arenosols based on the SOTER polygons.

\section{Soil Chemical and Physical Properties}

A summary of soil physical and chemical properties is given in Tables 4 and 5. The average sand content is highest in the topsoils of Arenosols in Angola, Zimbabwe, 


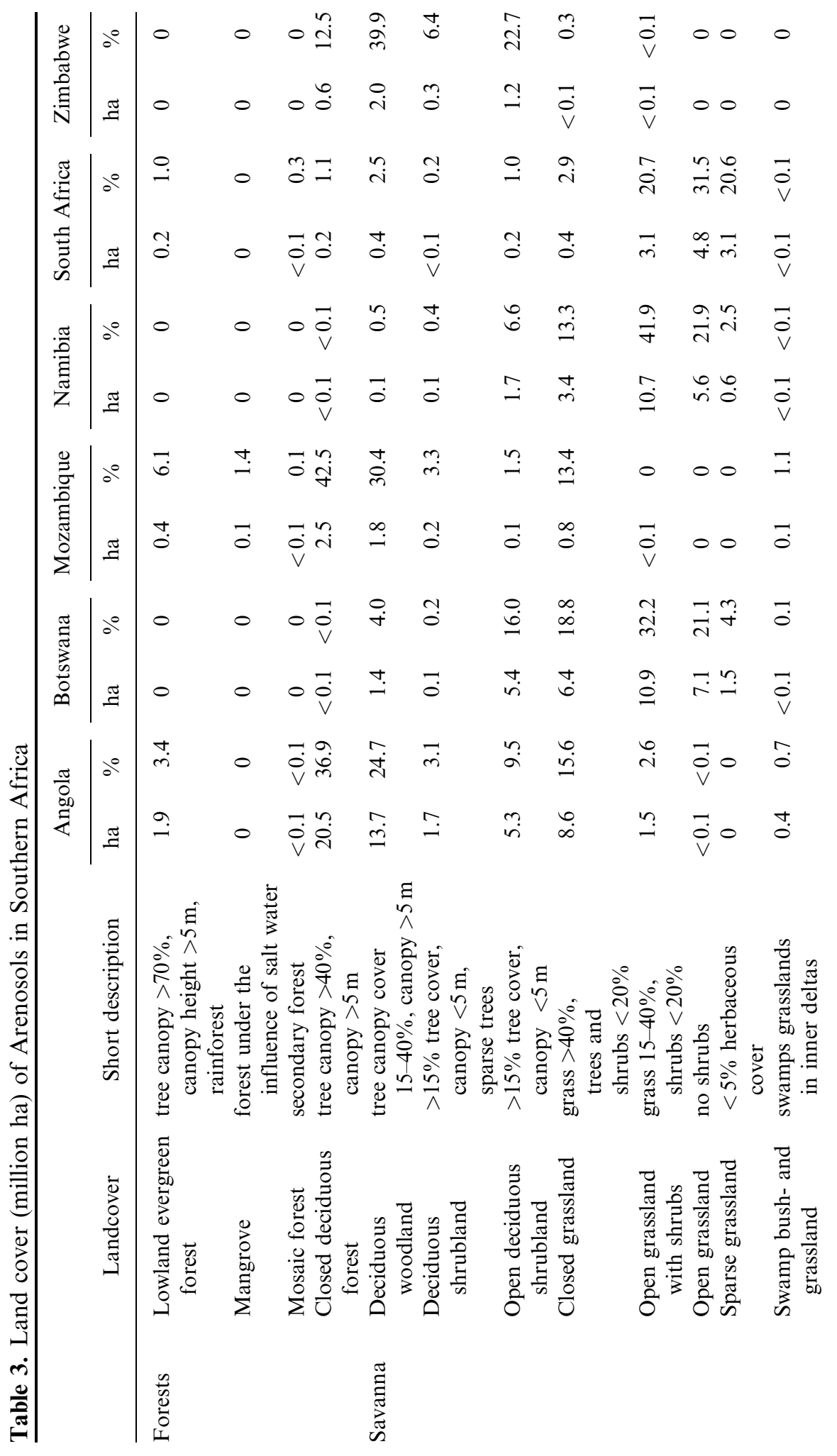




$$
\begin{aligned}
& \vec{\infty} 000 \quad \overrightarrow{0} \overrightarrow{0} \stackrel{\square}{0} \\
& \dot{0} 000 \overrightarrow{\dot{v}} \overrightarrow{\dot{v}} \quad \vec{i}
\end{aligned}
$$

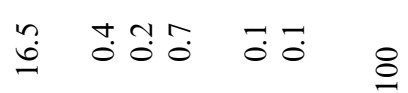

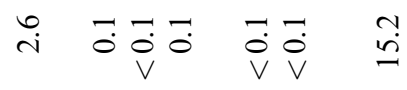

$$
\begin{aligned}
& \overrightarrow{0} \quad 0 \hat{\infty} \overrightarrow{+} \overrightarrow{\dot{\theta} \overrightarrow{0}} \&
\end{aligned}
$$

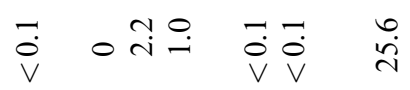

$$
\begin{aligned}
& \text { - } 000 \text { वี \& } \\
& \text { - } 000 \quad \overrightarrow{0} \overrightarrow{0} \quad \stackrel{\infty}{i} \\
& m \circ 0 \vec{v} \circ \overrightarrow{\dot{v}} \& \\
& =00 \vec{\nabla} \circ \vec{\nabla} \quad \vec{m} \\
& \dot{r} 000 \quad 00 \& \\
& \stackrel{9}{-} 00 \overrightarrow{\mathrm{v}} \text { oo in }
\end{aligned}
$$

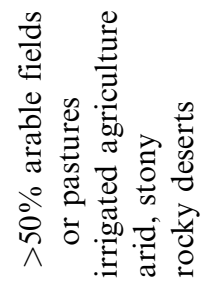

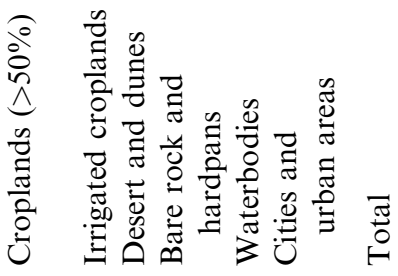

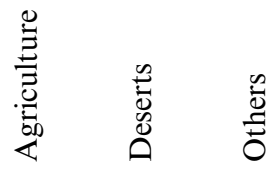




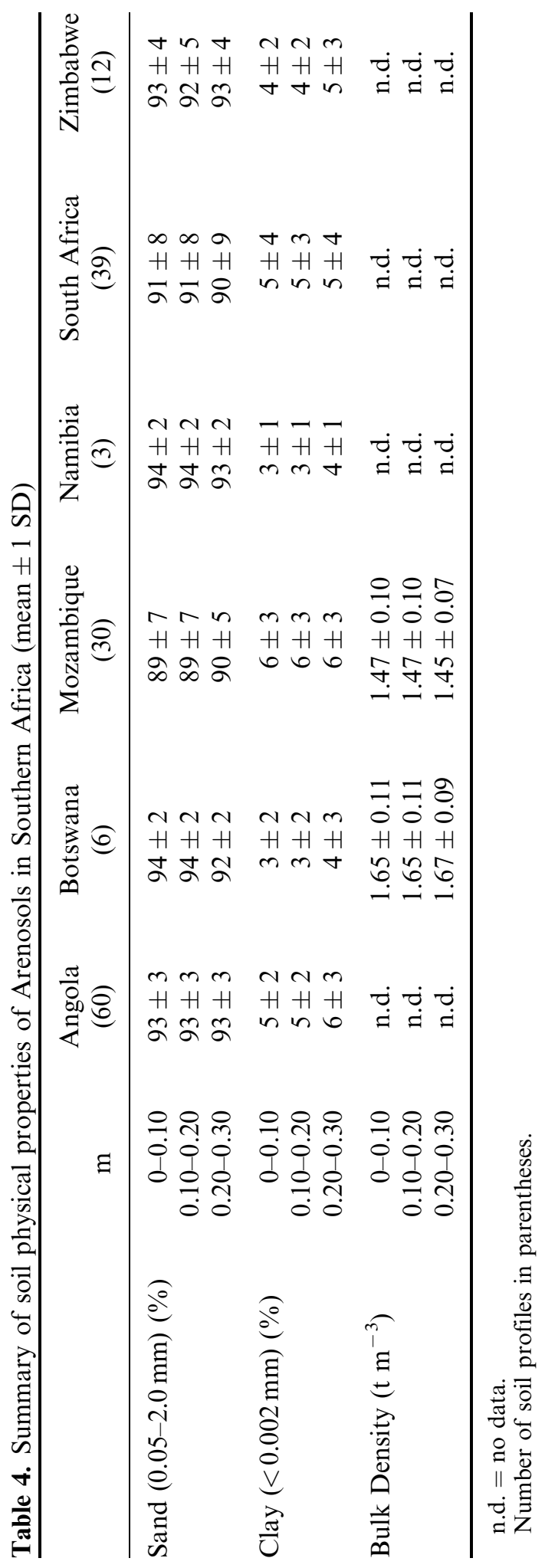




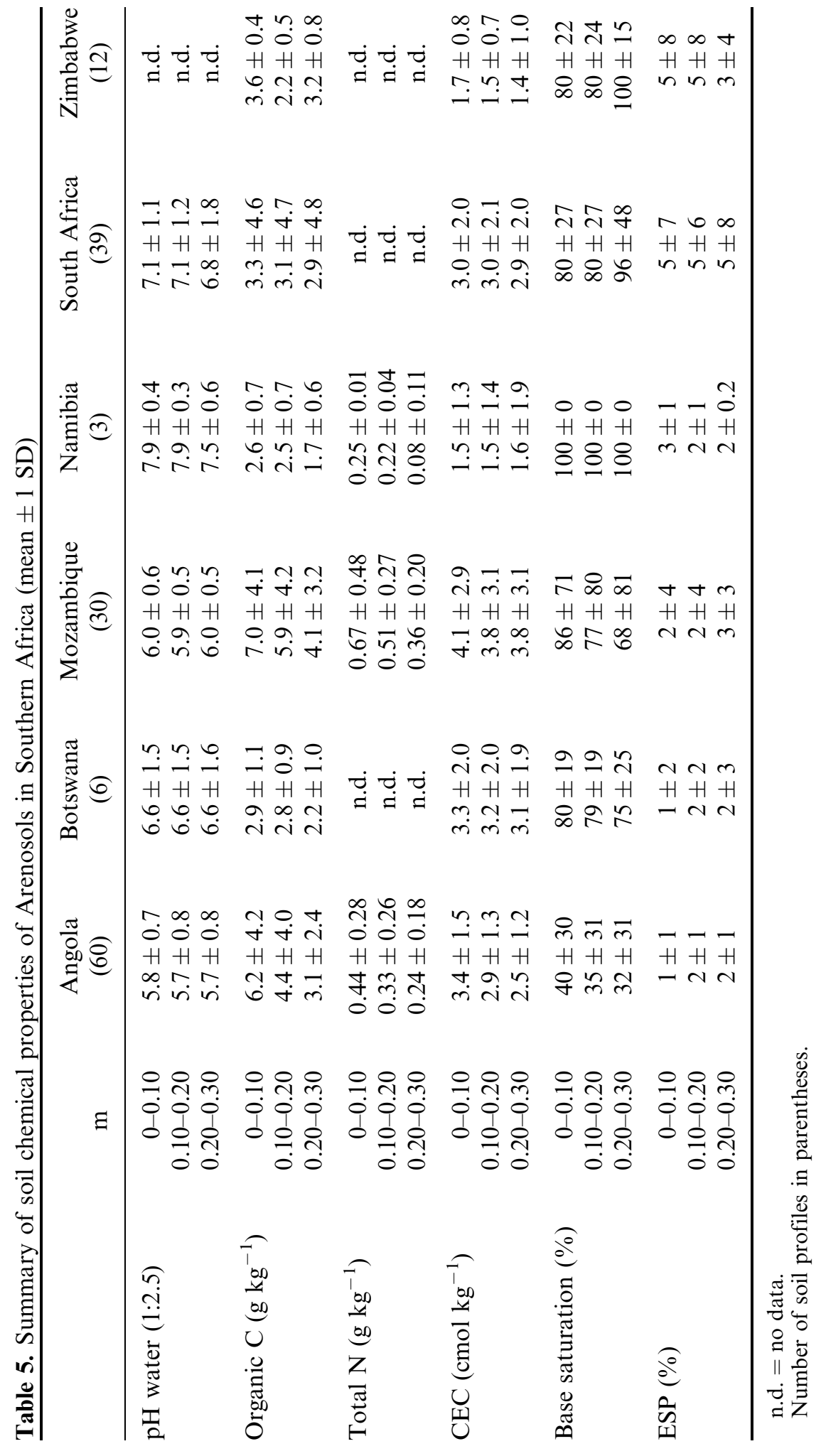



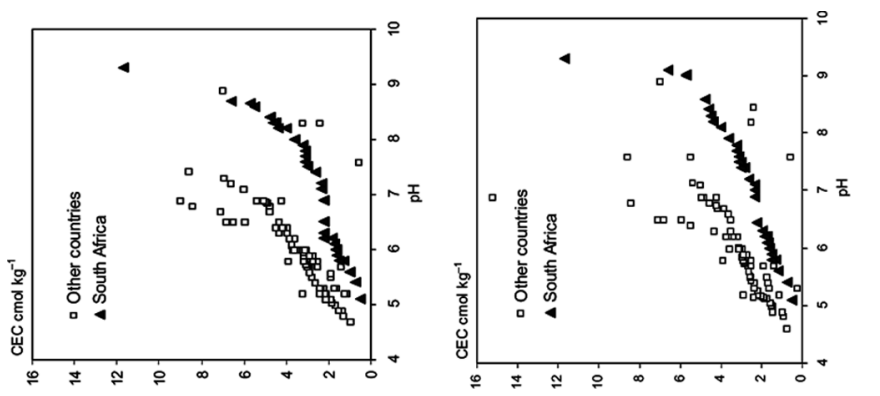

볼
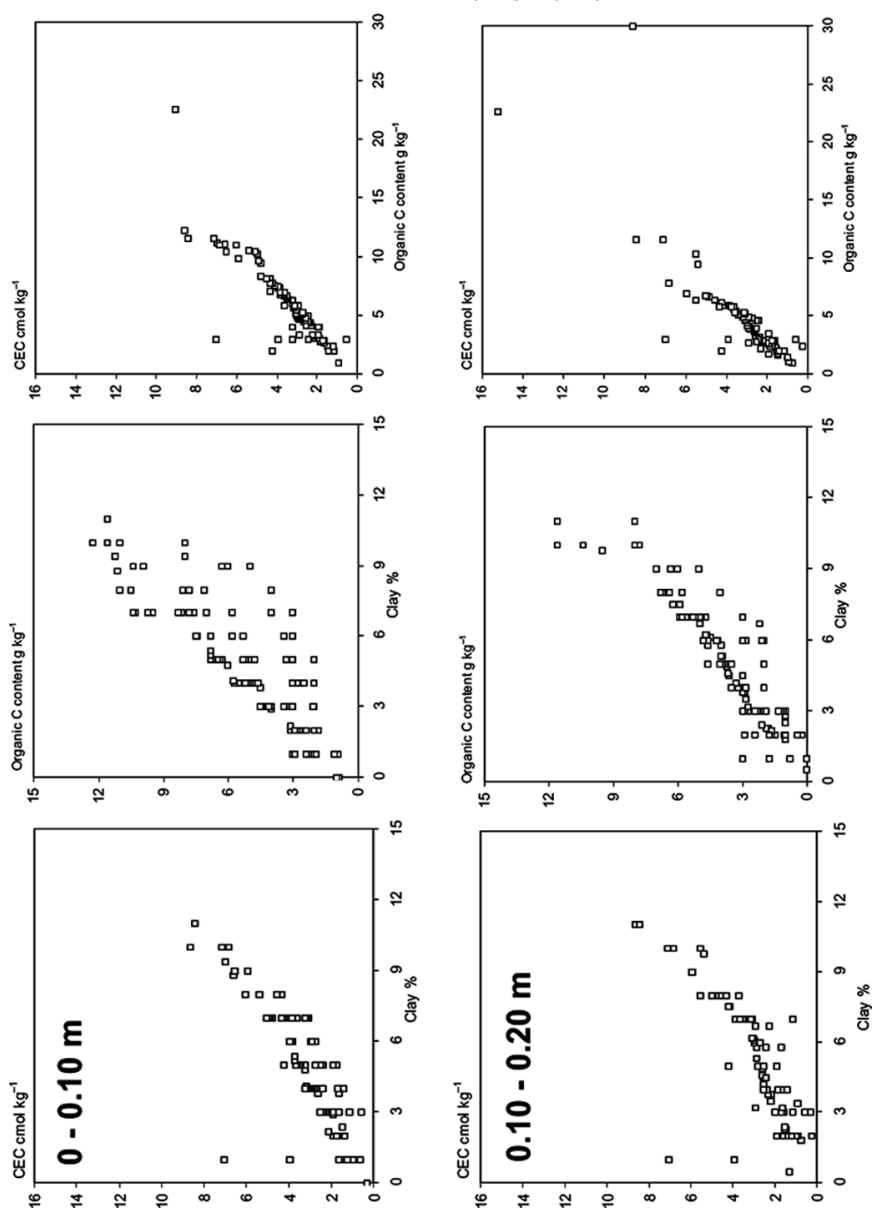

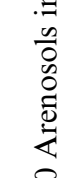

는

ถิ

กิ

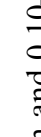

$\Xi$

웅

$\frac{0}{7}$ 
Namibia, and Botswana $(>92 \%)$, and lowest in the Arenosols of Mozambique $(<90 \%)$. Although this may appear as an insignificant difference, the lower sand content (and thus higher silt and clay content) influences important characteristics such as $\mathrm{C}$ content and nutrient retention (Figure 2). Few bulk density data were available and most of the Arenosols have fairly high bulk densities, which is common for sandy soils.

The average Arenosol topsoils in Namibia and South Africa are neutral to alkaline with a soil reaction over 7 . These soils have also base saturations of almost $100 \%$. In Angola and Zimbabwe, the average topsoil pH of Arenosols is below 6, whereas in the other countries Arenosols have mostly a topsoil pH between 6 and 7. Organic $\mathrm{C}$ is uniformly low in Arenosols of Southern Africa and rarely exceeds $10 \mathrm{~g} \mathrm{~kg}^{-1}$. Higher $\mathrm{C}$ contents are generally found in the soils with higher clay content (Figure 2). The CEC and the organic $\mathrm{C}$ contents correlated well with the clay content in the $0-0.10$ and $0.10-0.20 \mathrm{~m}$ soil horizons. Higher organic $\mathrm{C}$ levels also increased the CEC, whereas soil acidity seems to decrease the CEC in these Arenosols. In the graph relating the CEC to the $\mathrm{pH}$, there seem to be two groups; several of the lower values are from Arenosols in South Africa where CEC is determined at $\mathrm{pH} 8$ (in the other countries it is determined at $\mathrm{pH} 7$ ). The trend, however, is the same: a significant increasing $\mathrm{CEC}$ with higher $\mathrm{pH}$ values. The total $\mathrm{N}$ content of Arenosols in Southern Africa is typically below $0.7 \mathrm{~g} \mathrm{~kg}^{-1}$. The cation exchange capacity ranges from about $1.5 \mathrm{cmol} \mathrm{kg}^{-1}$ in the Arenosols of Namibia to $4.1 \mathrm{cmol} \mathrm{kg}^{-1}$ on average in the topsoils of Arenosols in Mozambique.

\section{Discussion}

In this article, the spatial distribution and land cover of sandy soils in Southern Africa were presented with a summary of their main soil physical and chemical properties. The extent of Arenosols in Southern Africa is considerable and amount to 169 million ha and this is the most accurate and up-to-date estimate. Earlier estimates have shown that the extent of Arenosols in Southern Africa was estimated at 195 million ha (FAO-Unesco, 1977). The biggest difference occurs in South Africa where the extent of Arenosols in our estimate is 18 million ha compared to 33 million ha in 1977 (FAO-Unesco, 1977).

Agriculture contributes about $35 \%$ of the gross domestic product of Southern Africa. It employs 70 to $80 \%$ of the total labor force and contributes about $30 \%$ to the region's foreign exchange earnings (Abalu and Hassan, 1998). About 6.5 million ha of Arenosols in Southern Africa are under cropland; the majority of these soils are under savannah vegetation. Due to the poor physical and chemical properties of the soil, the soil requires careful management to maintain and increase crop production. Nutrient inputs are essential (Hartemink, 2006) as are the additions of organic input to maintain or improve the soil physical properties. Extensive rainfed production of annual crops is possible and groundnuts, cassava, and tobacco are often considered best adapted to Arenosols. Perennial crops on Arenosols include cashews, coconuts, citrus, eucalyptus, and pine (van Wambeke, 1992) and generally tree crops form better protection for the soil than annual crops (Hartemink, 2005). Under natural conditions and in arid and semi-arid areas, it is difficult to establish dense plant communities on Arenosols due to the exploitation for firewood, grazing, or the destructive effects on the tree layer by large vertebrates and periodic burning (Almendros et al., 2003). As many Arenosols are inherently poor and are 
cultivated with limited or no nutrient inputs (Bationo and Buerkert, 2001; Mokwunye, 1991; Stoorvogel, Smaling, and Janssen, 1993), these soils are generally not very productive.

Some have argued that the determinants of food security in Southern Africa lie primarily outside the domain of agricultural production, i.e., food insecurity is the result of a combination of political, social, and economic factors at various level. Therefore, a focus on improving crop yields should include economics (e.g., inflation, market failures) and socio-political factors (conflict, Hiv/Aids) (Misselhorn, 2005). Here we have shown that there is some 6.5 million ha in Southern Africa that are inherently poor and used for agriculture. Such soils need agricultural inputs if they were to become productive.

There has been considerable research efforts on the sustainable management of sandy soils in West Africa (Bationo, 2004; Vanlauwe, Diels, Sanginga, and Merckx, 2002). Research efforts in Southern Africa have been less intense although there is a fair body of literature from Zimbabwe (e.g., Jeranyama, Hesterman, Waddington, and Harwood, 2000; Nyamangara, Gotosa, and Mpofu, 2001; Zingore, Manyame, Nyamugafata, and Giller, 2005) and South Africa (Mills and Fey, 2004; Moodley, Johnston, Hughes, and Titshall, 2004; Verdoodt, Van Ranst, and Van Averbeke, 2003). Exchange of experiences and research results on the properties and management may be beneficial for land use planning and farmers in both African regions.

\section{References}

Abalu, G. and R. Hassan. 1998. Agricultural productivity and natural resource use in southern Africa. Food Policy 23:477-490.

Almendros, G., Kgathi, D., Sekhuela, M., Zancadu, M. C., Tinoco, P., and M. Pardo. 2003. Biogeochemical assessment of resilient humus formations from virgin and cultivated northern Botswana soils. Journal of Agricultural \& Food Chemistry 51:4321-4330.

Bationo, A. (Ed.). 2004. Managing nutrient cycles to sustain soil fertility in Sub-Sahara Africa. ASP-AfNet-CIAT,Nairobi.

Bationo, A. and A. Buerkert. 2001. Soil organic carbon management for sustainable land use in Sudano-Sahelian West Africa. Nutrient Cycling in Agroecosystems 61:131-142.

Batjes, N. H. 2002. Revised soil parameter estimates for the soil types of the world. Soil Use \& Management 18:232-235.

Batjes, N. H. 2004. SOTER-based soil parameter estimates for Southern Africa (version 1.0). Report 2004/04. ISRIC - World Soil Information. Wageningen.

Burt, R., M. A. Wilson, C. W. Kanyanda, J. K. R. Spurway, and J. D. Metzler. 2001. Properties and effects of management on selected granitic soils in Zimbabwe. Geoderma 101:119-141.

Dijkshoorn, J. 2003. SOTER database for Southern Africa (SOTERSAF). Technical report. ISRIC, Wageningen.

Eswaran, H., R. Almaraz, E. Vandenberg, and P. Reich. 1997. An assessment of the soil resources of Africa in relation to productivity. Geoderma 77:1-18.

FAO. 2001. Lecture notes on the major soils of the world. World Soil Resources Reports 94. FAO, Rome.

FAO-ISRIC. 2003. Soil and terrain database for Southern Africa (1:2 million scale). FAO Land and Water Digital Series 25 (CD ROM), FAO, Rome.

FAO-Unesco. 1977. Soil map of the world. Volume VI: Africa, 1: 5000 000, Rome.

Hartemink, A. E. 2005. Plantation agriculture in the tropics - environmental issues. Outlook on Agriculture 34:11-21. 
Hartemink, A. E. 2006. Assessing soil fertility decline in the tropics using soil chemical data. Advances in Agronomy 89:179-225.

Jeranyama, P., O. B. Hesterman, S. R. Waddington, and R. R. Harwood. 2000. Relay-intercropping of sunhemp and cowpea into a smallholder maize system in Zimbabwe. Agronomy Journal 92:239-244.

Mayaux, P., 2003. EUR $20665 E N-A$ land-cover map of Africa. Office for Official Publications of the European Communities, Luxembourg.

Mills, A. J. and M. V. Fey. 2004. Effects of vegetation cover on the tendency of soil to crust in South Africa. Soil Use \& Management 20:308-317.

Misselhorn, A. A. 2005. What drives food insecurity in southern Africa? a meta-analysis of household economy studies. Global Environmental Change Part A 15:33-43.

Mokwunye, A. U. 1991. Alleviating soil fertility constraints to increased crop production in West Africa. Developments in plant and soil sciences. Kluwer Academic, Dordrecht, vii.

Moodley, M., M. A. Johnston, J. C. Hughes, and L. W. Titshall. 2004. Effects of a water treatment residue, lime, gypsum, and polyacrylamide on the water retention and hydraulic conductivity of two contrasting soils under field conditions in KwaZulu-Natal, South Africa. Australian Journal of Soil Research 42:273-282.

Nyamangara, J., J. Gotosa, and S. E. Mpofu. 2001. Cattle manure effects on structural stability and water retention capacity of a granitic sandy soil in Zimbabwe. Soil \& Tillage Research 62:157-162.

Oldeman, L. R. and V. W. P. van Engelen. 1993. A world soils and terrain digital database (SOTER) - An improved assessment of land resources. Geoderma 60:309-325.

Peech, M. 1965. Exchange acidity: Barium chloride-triethanolamine method, pp. 910-911, in C. A. Black, ed., Methods of soil analysis, Part 2. American Society of Agronomy, Madison, WI.

Soil Survey Staff. 1999. Soil taxonomy. 2nd ed. Agriculture Handbook Number 436. USDA National Resources Conservation Services, Washington, DC.

Stoorvogel, J. J., E. M. A. Smaling, and B. H. Janssen. 1993. Calculating soil nutrient balances in Africa at different scales. 1. Supra-national scale. Fertilizer Research 35:227-235.

van Engelen, V. and A. E. Hartemink. 2000. The global soils and terrain database (SOTER). ACLEP Newsletter 9:22-27.

van Wambeke, A. 1992. Soils of the tropics-properties and appraisal. McGraw Hill, Inc., New York.

Vanlauwe, B., J. Diels, N. Sanginga, and R. Merckx. (Eds.). 2002. Integrated plant nutrient management in Sub-Saharan Africa: From concept to practice. CABI Publishing, Wallingford.

Verdoodt, A., E. Van Ranst, and W. Van Averbeke. 2003. Modelling crop production potentials for yield gap analysis under semiarid conditions in Guquka, South Africa. Soil Use \& Management 19:372-380.

Zingore, S., C. Manyame, P. Nyamugafata, and K. E. Giller. 2005. Long-term changes in organic matter of woodland soils cleared for arable cropping in Zimbabwe. European Journal of Soil Science 56:727-736. 